\title{
Effect of Packet Size on Various MANET Routing Protocols
}

\author{
Manoj Tolani \\ Assistant Professor \\ Electronics and communication \\ PSIT College of Engineering (PSIT-COE), Kanpur
}

\author{
Rajan Mishra \\ Assistant Professor \\ Electronics and communication \\ Madan Mohan Malviya Engineering College, \\ Gorakhpur
}

\begin{abstract}
MANET is a peer to peer, multi-hop mobile wireless networks in which packets are transmitted in store and forward manner from source to destination. When processing the packets from one node to another node packet size is very important parameter because changing the packet size effect the performance of the MANET network. Aim of this research paper to analyze the effect of packet size in MANET network. We analyze the MANET network for three routing protocols AODV, OLSR \& DSR. For this purpose we take 50 nodes MANET network \& each node work as MANET station.
\end{abstract}

\section{Keywords}

MANET, AODV, PACKET SIZE, OLSR, DSR.

\section{INTRODUCTION}

MANET stands for Mobile Ad-hoc network. Ad-hoc network is a type of network in which packets are delivered to their destination through wireless multi-hop connectivity. Mobile nodes work as a hosts and also work as a router. These nodes relay the traffic to other nodes. MANET have high throughput because it is a type of WLAN which have WLAN sharing capacity and relatively higher bandwidth. In this research paper we discuss we discuss the processing of packets in MANET. In a MANET data is transmitted in form of packets. Packet contains the information of source node, their destination node and other information related to routing of packets. As the packet size increase the data contain in packet increases and overhead bits reduces with respect to data. It is also very important to note that when processing small packet size traffic increases and also network load to transfer same amount of data is also increases. As wireless environment is also very noisy so that whenever data loss takes place due to this noisy environment we need to retransmit of data and large packets more effected with respect small packets so that large packet loss causes more data loss. To analyzing the effect of packet size we vary the packet size of the nodes that generate the traffic and check its effect on various routing protocols. For analyzing we take 50 nodes MANET network and vary their packet size, finally we compare performance for different routing protocols.

\section{ROUTING PROTOCOLS}

There are various existing routing protocols that can be classified either as a proactive or reactive routing protocol. In case of proactive routing protocol routes are already known and data packets are transmitted through these routes. The advantage of this type of routing protocols is that data is transmitted without delay as the routes are already known, but the disadvantage is that because dynamic nature of MANET mobile nodes change their location every instant so that need regular updates and most of the capacity of channel is waste in routing information. It is very useful where the nodes are stationary or slow moving. On other hand proactive routing protocols are work on demand basis, routes are not already formed, whenever there is need of data transmission the route formation take place and then data transmitted so that there is delay in data transmission, but network load reduces and not need to perform regular updates. Here we discuss three routing protocols AODV, DSR are reactive routing protocols and OLSR is proactive routing protocol.

\subsection{AODV (Ad-Hoc on Demand Distance Vector Routing Protocol)}

Ad-hoc on demand distance vector routing protocol is a reactive routing protocol. It is having larger delay as compared delay as compared to OLSR routing protocol because OLSR is a proactive routing protocol so that AODV is not suitable for real time operations.

\subsection{OLSR (Optimized link state routing protocol)}

Optimized link state routing protocol is a proactive routing protocol and it has very less delay in packet transmission. As packet size increases throughput increases and delay also increases but it is not too large as in case of DSR. It is suitable for real time applications.

\subsection{DSR (Destination source routing)}

Destination source routing is a reactive routing protocol. It has larger delay as compared to the OLSR \& AODV but when increasing packet size after specified limit delay in packets increases sharply.

\section{WLAN PARAMETERS}

Different wireless LAN parameters and all other important parameters are given below in table. We analyze the network for different routing protocols ad different packet size. 
Table 1: Various important parameters set in different scenarios

\begin{tabular}{|c|c|}
\hline \multicolumn{2}{|c|}{ SIMULATION PARAMETERS } \\
\hline No. Of Nodes & 50 \\
\hline Playground size & $740 \mathrm{~m} * 370 \mathrm{~m}$ \\
\hline Simulation time & $600 \mathrm{sec}$ \\
\hline \multicolumn{2}{|c|}{ ROUTING MAC PROTOCOL } \\
\hline Routing Protocol & AODV,OLSR,DSR \\
\hline MAC Protocol & $802.11 \mathrm{~b}$ \\
\hline Data Rate & $11 \mathrm{Mbps}$ \\
\hline \multicolumn{2}{|c|}{ MOBILITY PATTERN } \\
\hline Mobility type & --NA-- \\
\hline Speed & --NA-- \\
\hline Pause Time & --NA-- \\
\hline \multicolumn{2}{|c|}{ RADIO CHARACTERISTICS } \\
\hline Transmitted Power & $5 \mathrm{~mW}$ \\
\hline $\begin{array}{l}\text { Packet Reception } \\
\text { Power Threshold }\end{array}$ & $-95 \mathrm{dBm}$ \\
\hline \multicolumn{2}{|c|}{ MANET TRAFFIC GENERATION PARAMETERS } \\
\hline Start Time & $10 \mathrm{sec}$ \\
\hline $\begin{array}{c}\text { Packet Inter Arrival } \\
\text { Time }\end{array}$ & $\operatorname{Exp}(1) \sec$ \\
\hline Packet Size & $\begin{array}{c}256,512,1024,2048,3072, \\
4096,8192 \text { bits }\end{array}$ \\
\hline
\end{tabular}

\section{DATA ANALYSIS THROUGH SIMULATION RESULTS}

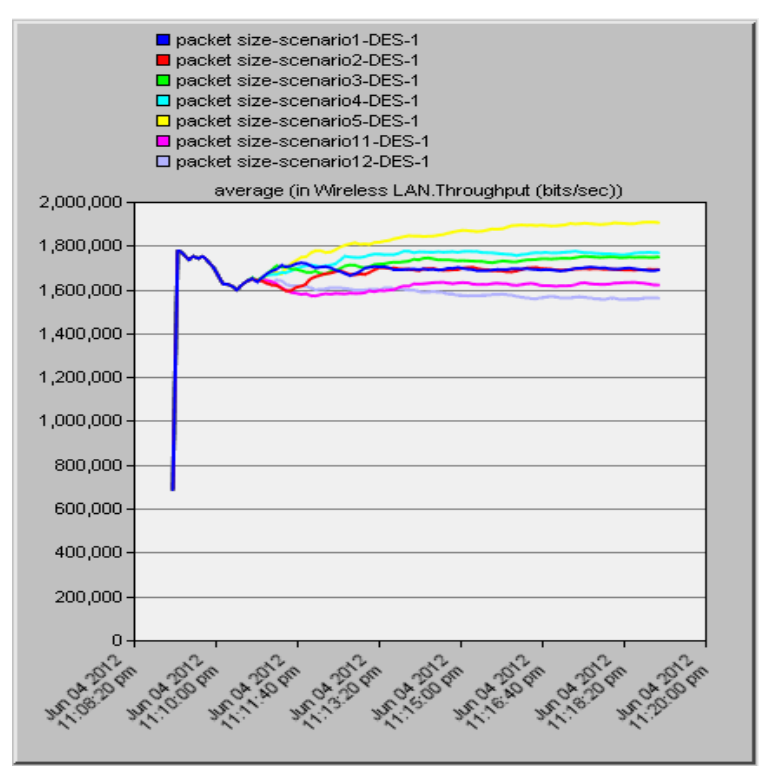

Fig 1: OLSR throughput for different packet size

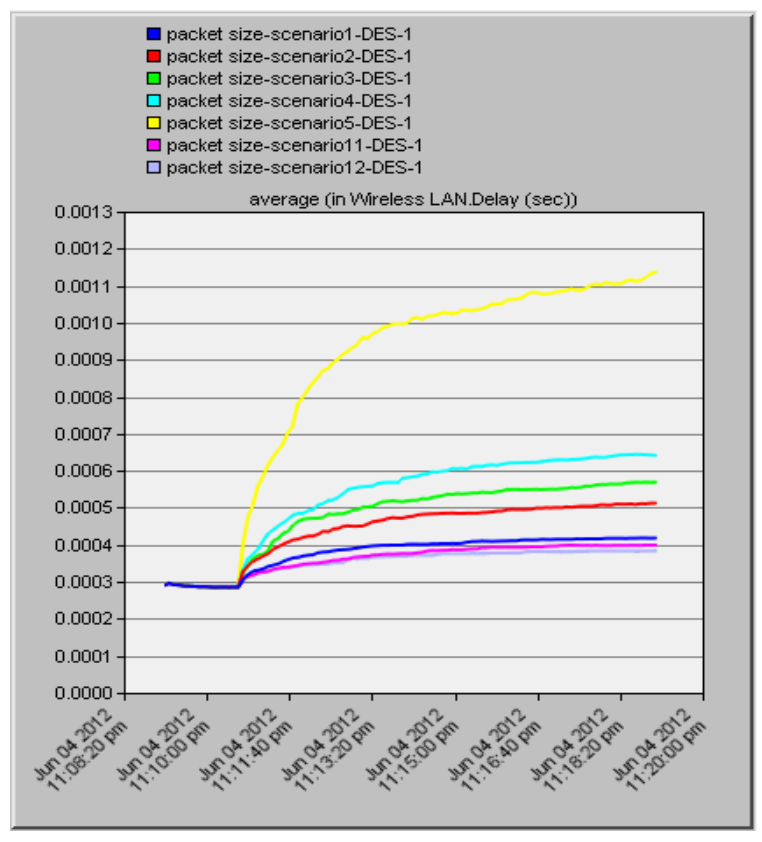

Fig 2: OLSR delay for different packet size

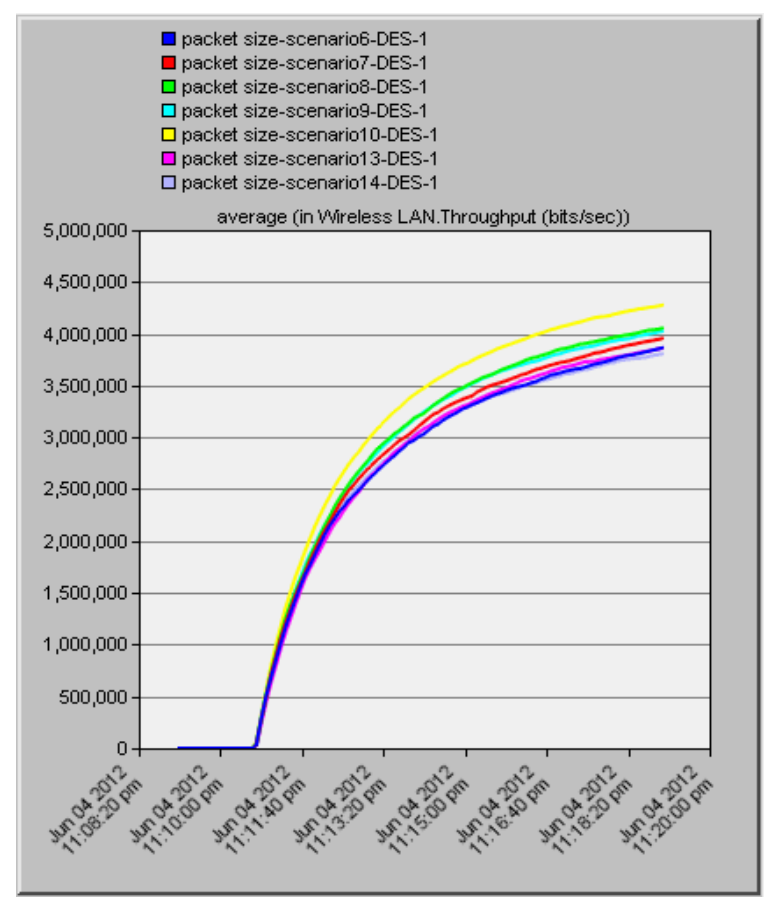

Fig 3: AODV Throughput for different packet size 


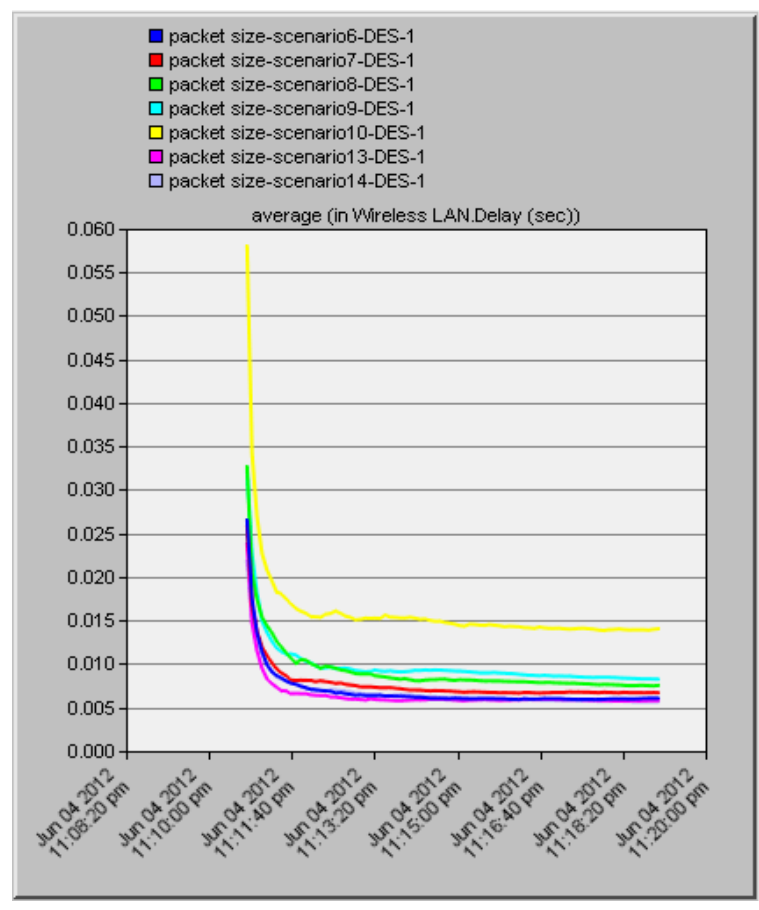

Fig 4: AODV Delay for different packet size

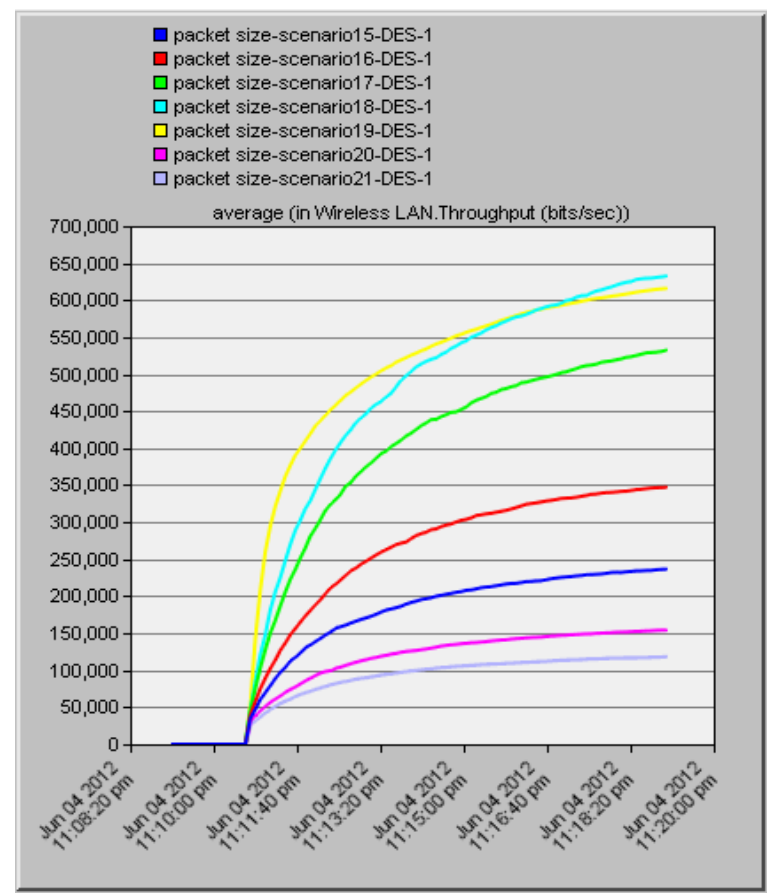

Fig 5: DSR Throughput for different packet size

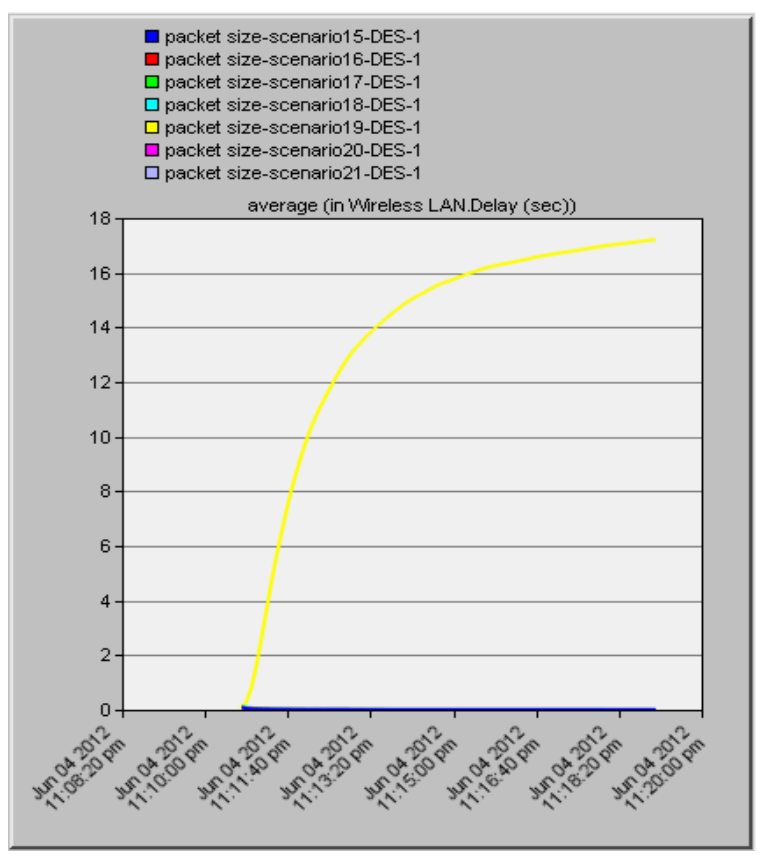

Fig 6: DSR delay for different packet size

\begin{tabular}{|l|l|l|l|l|l|l|}
\hline 256 & 512 & 1024 & 2048 & 3072 & 4096 & 8192 \\
\hline & & & & & & \\
& & & & & & \\
\hline
\end{tabular}

Fig 7: Color Code for different packet size

As shown in above results that packet size varies from 256 bits to 8192 bits. When processing small packets it takes less time to transmission but need to more packets to transfer same amount of traffic. When packet size is small it easily transfers at large distance. In congestion less medium as the load increases with packet size throughput also increases while in case of congested medium when load increases throughput decreases. Wireless environment is very noisy so if the packets corrupt due to noise environment, corrupted packets need to be retransmitted. So that as the packet size increases causes reduction in throughput when medium is congested.

congestion less congested

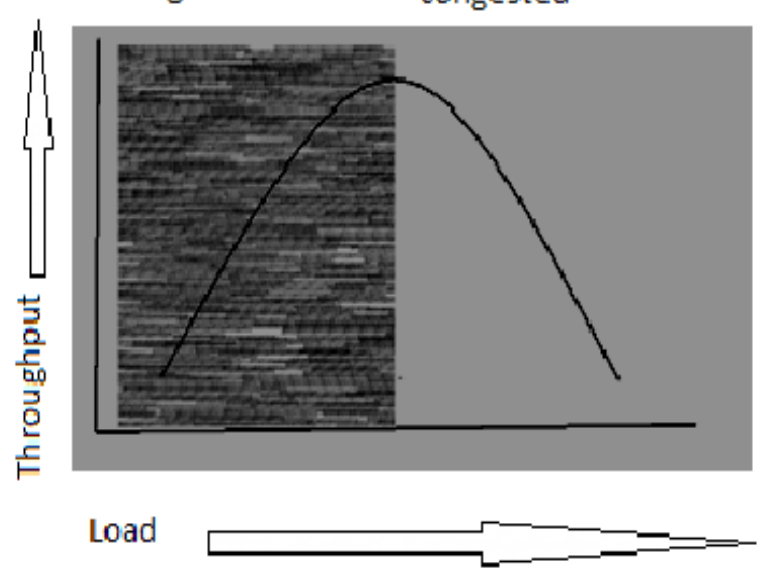

Fig 8: Graph between Load \& Throughput in both congestion \& congestion less medium 
Table 2: Data analysis of different packet size for OLSR

\begin{tabular}{|l|l|l|l|}
\hline $\begin{array}{c}\text { Packet } \\
\text { Size }\end{array}$ & $\begin{array}{c}\text { Maximum } \\
\text { Throughput } \\
(\mathrm{kbps})\end{array}$ & $\begin{array}{c}\text { Delay } \\
(\mathrm{ms})\end{array}$ & $\begin{array}{c}\text { Data } \\
\text { Dropped } \\
(\mathrm{kbps})\end{array}$ \\
\hline 256 & 1560 & 0.38 & 0.5 \\
\hline 512 & 1640 & 0.40 & 1 \\
\hline 1024 & 1700 & 0.42 & 2 \\
\hline 2048 & 1700 & 0.51 & 12 \\
\hline 3072 & 1740 & 0.56 & 24 \\
\hline 4096 & 1780 & 0.65 & 39 \\
\hline 8192 & 1900 & 1.10 & 108 \\
\hline
\end{tabular}

Table 3: Data analysis of different packet size for AODV

\begin{tabular}{|l|l|l|l|}
\hline $\begin{array}{c}\text { Packet } \\
\text { Size }\end{array}$ & $\begin{array}{c}\text { Maximum } \\
\text { Throughput } \\
(\mathrm{kbps})\end{array}$ & $\begin{array}{c}\text { Delay } \\
(\mathrm{ms})\end{array}$ & $\begin{array}{c}\text { Data } \\
\text { Dropped } \\
(\mathrm{kbps})\end{array}$ \\
\hline 256 & 3750 & 6 & 4 \\
\hline 512 & 3800 & 6 & 6 \\
\hline 1024 & 3800 & 6.5 & 10 \\
\hline 2048 & 3950 & 7 & 22 \\
\hline 3072 & 4050 & 7.5 & 41 \\
\hline 4096 & 4000 & 8 & 61 \\
\hline 8192 & 4250 & 14 & 165 \\
\hline
\end{tabular}

Table 4: Data analysis of different packet size for DSR

\begin{tabular}{|l|l|l|l|}
\hline $\begin{array}{c}\text { Packet } \\
\text { Size }\end{array}$ & $\begin{array}{c}\text { Maximum } \\
\text { Throughput } \\
(\mathrm{kbps})\end{array}$ & \multicolumn{1}{|c|}{ Delay } & $\begin{array}{c}\text { Data } \\
\text { Dropped } \\
(\mathrm{kbps})\end{array}$ \\
\hline 256 & 110 & $5 \mathrm{~ms}$ & 0.1 \\
\hline 512 & 150 & $5 \mathrm{~ms}$ & 0.5 \\
\hline 1024 & 240 & $5 \mathrm{~ms}$ & 0.7 \\
\hline 2048 & 350 & $5 \mathrm{~ms}$ & 2.6 \\
\hline 3072 & 530 & $5 \mathrm{~ms}$ & 2.6 \\
\hline 4096 & 620 & $5 \mathrm{~ms}$ & 4.2 \\
\hline 8192 & 610 & $17 \mathrm{~s}$ & 118 \\
\hline
\end{tabular}

From the results it is clear that for OLSR routing protocol have very less delay, when packet size is 1024 bits it is having optimized value of throughput, delay \& data dropped. As when increasing packet size 2048 bits it have same throughput but data dropped increases 6 times. AODV routing protocol have much larger delay in comparison of OLSR and have higher data dropped. For packet size of 512 bits it has optimized value of throughput, delay \& data dropped. Throughput of DSR is much smaller in comparison of OLSR \& AODV.

\section{CONCLUSION \& FUTURE WORK}

From the data analysis of results it is clear that OLSR having very less delay but AODV have higher throughput for same packet sizes. So for real time operations OLSR is best routing protocol and for high traffic AODV is best routing protocol. Each routing protocol has optimized value of packet size for which its performance is best. Such as in case of AODV 512 bits is best packet size and for OLSR 1024 bits is best packet size. These all values are $f$ or congestion less medium, in congested medium higher packets causes high load and they are dropped so that wireless medium have very noisy environment packet size is very sensitive. In future we can analyze the packet size of Wi-MAX based MANET.

\section{REFERENCES}

[1]. Patrick Sondi, DhavyGantsou and Sylvain Lecomte, "Mobile Ad Hoc Network-Based Monitoring Of Battlefields Or Rescue Operations In Urban Scenarios", UKSim Fourth European Modelling Symposium on Computer Modelling and Simulation, pages pp 408-413, IEEE 2010.

[2]. Zahian Ismail, Rosilah Hassan, "Effects Of Packet Size On AODV Routing Protocol Implementation In Homogeneous And Heterogeneous MANET", 2011 Third International Conference on Computational Intelligence, Modelling\& Simulation, pages pp 351-356, IEEE 2011.

[3]. MostafaFazeli, HasanVaziri, “Assessment Of Throughput Performance Under OPNET Modeler Simulation Tools In Mobile Ad Hoc Networks (MANET's)", 2011 Third International Conference on Computational Intelligence, Communication Systems and Networks,pages pp 328-331, IEEE 2011.

[4]. AshishShrestha, FiratTekiner, "On MANET Routing Protocols for Mobility and Scalability" 2009 International Conference on Parallel and Distributed Computing, Applications and Technologies, pages pp 451-456, IEEE 2009.

[5]. R.K.Nadesh , D.Sumathy, M. B. BenjulaAnbu Malar, "Performance Analysis Of MANET (WLAN) Using Different Routing Protocols In Multi Service Environments-An Quantitative Study", Int. J. Advanced Networking and Applications Volume: 03, Issue: 02, Pages:1076-1079 (2011)

[6]. Anuj K. Gupta, Member, IACSIT, Dr. Harsh Sadawarti, Dr. Anil K. Verma, "Performance Analysis Of AODV, DSR \& TORA Routing Protocols", IACSIT International Journal of Engineering and Technology, Vol.2, No.2,pages pp 226-231 April 2010.

[7]. Al-Maashri, A. and Ould-Khaoua, M. (2006) "Performance Analysis Of MANET Routing Protocols in the presence of Self-Similar Traffic", Proceedings of the 31st IEEE Conference on Local Computer Networks,2006, 14-16 November 2006, pages pp. 801807, Tampa, Florida, USA.

[8]. Yi Wang, Hairong Chen, Xinyu Yang and Deyun Zhang, "Cluster Based Location-Aware Routing Protocol For Large Scale Heterogeneous Manet", Second International Multisymposium on Computer and Computational Science, Computer Society pages pp 366-373, IEEE (2007).

[9]. EmadAboelela, "Computer Networks A System Approach, Edition-3, Networks Simulation Experiment Mannual”, University of Massachusetts Dartmouth, 2003.

[10].TanviMalik,Gaurav Mittal, Monika Aggarwal "Simulation Based Performance Analysis of Ad-Hoc Routing Protocols in Various Moving Trajectories", Department of ECE, B.G.IET, Sangrur, India, Vol 1, Issue 7, 373-375, IJCSET August 2011 